Document downloaded from:

http://hdl.handle.net/10251/166577

This paper must be cited as:

Romero, G.; Fuertes-Miquel, VS.; Coronado-Hernández, OE.; Ponz-Carcelén, R.; BielSanchis, F. (2020). Analysis of hydraulic transients during pipeline filling processes with air valves in large-scale installations. Urban Water Journal. 17(6):568-575. https://doi.org/10.1080/1573062X.2020.1800762

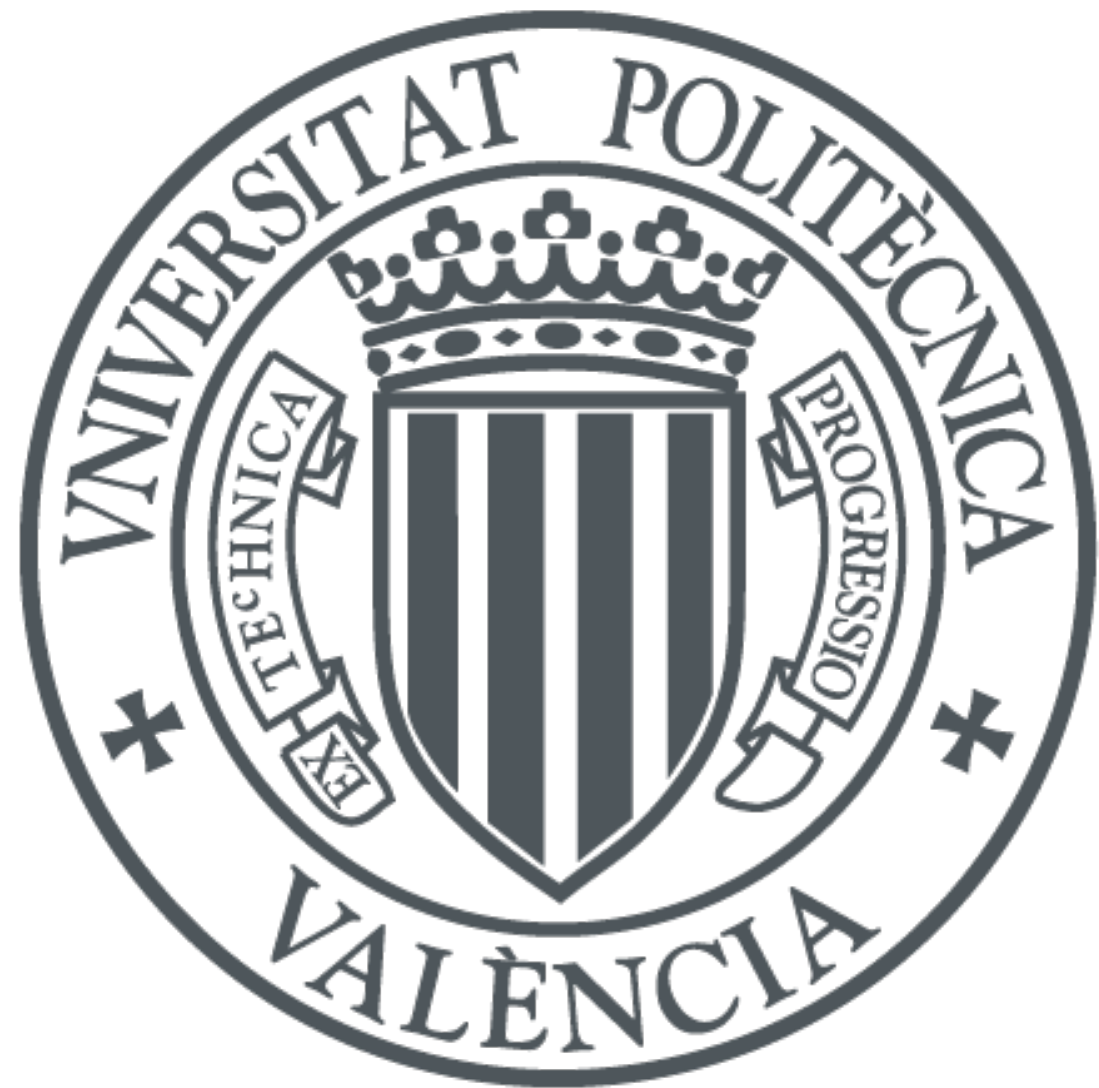

The final publication is available at

https://doi.org/10.1080/1573062X.2020.1800762

Copyright Taylor \& Francis

Additional Information 


\title{
Analysis of hydraulic transients during pipeline filling processes with air valves in large-scale installations
}

\author{
Guillermo Romero $^{\mathrm{a}}$, Vicente S. Fuertes-Miquel ${ }^{\mathrm{b}}$, Óscar E. Coronado-Hernández ${ }^{\mathrm{c}}$, Román \\ Ponz-Carcelén ${ }^{\mathrm{d}}$, Francisco Biel-Sanchis ${ }^{\mathrm{e}}$ \\ ${ }^{a}$ Department of Hydraulic Engineering and Environment, Universitat Politècnica de València, \\ Valencia, Spain, guirogarc@gmail.com; ${ }^{b}$ Department of Hydraulic Engineering and \\ Environment, Universitat Politècnica de València, Valencia, Spain, vfuertes@upv.es; ${ }^{c}$ Facultad \\ de Ingeniería, Universidad Tecnológica de Bolívar, Cartagena, Colombia, \\ ocoronado@utb.edu.co; ${ }^{d}$ Empresa Mixta Metropolitana S.A., EMIMET, Valencia, Spain, \\ rponz@emimet.es; ${ }^{e}$ Empresa Mixta Metropolitana S.A., EMIMET, Valencia, Spain, \\ fbiel@emimet.es
}

\begin{abstract}
During the filling process in pressurized hydraulic systems, sudden pressure changes generated inside the pipes can cause significant damage. To avoid these excessive overpressures, air valves should be installed to allow air exchange between the inside and outside during the filling process. This study presents a mathematical model to analyse the hydraulic transients during filling processes. This model, which has already been validated in small laboratories, is now applied to real large-scale systems that consist of DN400 and DN600 pipelines from Empresa Mixta Metropolitana S.A (EMIMET - Group Global Omnium), which is the company that manages the water supply of the metropolitan area of Valencia (from the Drinking Water Treatment Station to the municipalities). The mathematical model for large pipes is validated by comparing the experimental measurements and the results of model.
\end{abstract}

\section{KEYWORDS}

Hydraulic transients; filling of pipelines; trapped air; air valves; mathematical model; large-scale facilities.

\section{Introduction}

The analysis of the hydraulic and thermodynamic variables involved in all processes of actual installations is a control measure for the prevention of undesirable situations (Zhou, Hicks and Steffler 2002; Trindade and Vasconcelos 2013). During the processes of pipeline filling and emptying, extreme pressures can be generated inside the pipes (Malekpour et al. 2019) due to the movement of the water column and the size variation of the air pockets within the pipes (Fuertes-Miquel et al. 2019a). In the emptying process, the air pocket volume increases when the size of the water column decreases, causing pressure drops within the pipes (Coronado-Hernández et al. 2018; Fuertes-Miquel et al. 2019b; Laanearu et al. 2012). The opposite occurs in the filling process; in this case, the length of the water column increases, and the air pocket volume decreases, which generates substantial overpressures inside the pipe (Zhou et al. 2013a; Zhou and Liu 2013b; Malekpour, Karney and Nault 2015). These overpressures and pressure drop that 
are generated during the filling and emptying processes, respectively, may cause ruptures or collapses (Fuertes-Miquel et al. 2019a).

Air valves can be used to prevent this phenomenon (Wylie and Streeter 1993; Chaudhry 2014). These valves are placed at various points of the installation, such as the highest points and at abrupt slope changes (AWWA 2001). The purpose of the air valves is to allow the exhaust (Apollonio et al. 2016) and intake of air during the processes of filling and emptying and avoid potentially harmful overpressures and pressure drops inside the pipelines, respectively (Ramezani, Karney and Malekpour 2016; Balacco et al. 2015).

During the filling process, if there are no air valves, the compression of the air pocket causes overpressure (Hou et al. 2014; Tijsseling et al. 2016; Vasconcelos and Wright 2008; Wang et al. 2017). In contrast, when the system has air valves, these valves allow the release of trapped air to the outside and relieve the pressure inside the pipe, thereby preventing large overpressures (Coronado-Hernández et al. 2019; Ramezani, Karney and Malekpour 2016; Tran 2017). When air valves are oversized, achieved pressure surges can be greater compared to the scenario without these hydraulic devices (Fuertes-Miquel et al. 2019a). Therefore, air valves should be carefully selected in order to have an appropriate pipe class in hydraulic installations.

The simulation of this process can be performed using 1D flow equations, or 2D and 3D computational fluid dynamics (CFD) flow models. 1D flow equations are recommended for pipelines where the variation of an air-water interface has no important changes during a transient event, whereas CFD models can be used to calculate absolute pressure pulses accurately for complex interactions of a mix of water and air changing over time in hydraulic installations (Besharat et al. 2016; Martins at al. 2017; Malekpour et al. 2019). The advantage of these techniques is the high level of detail that the process analysis can achieve. However, these techniques are quite complex and require enormous computing power. Recent studies have used CFD methods to investigate certain aspects of pipeline filling (Zhou, Liu and Ou 2011; Saemi et al. 2019), and pressure surges inside air valves (García-Todolí et al. 2018).

This research focuses on the simulation of filling processes in different supply systems. The filling processes are studied using the mathematical model developed by the authors, which is suitable of simulating the behaviour of the system (water column and air pocket) during the hydraulic transient. The main assumptions of the model include the following: the equation of the rigid water column model; the polytropic coefficient equation is used to describe the behaviour of the air pocket (León et al. 2010; Martins et al. 2015; Zhou et al. 2011); and the piston flow model is taken into account so that the air-water separation interface is perpendicular to the axis of the pipe. A stratified flow cannot be simulated using the current model, which occurs in horizontal branch pipes (Balacco et al. 2018). The elastic effects of the system are disregarded (Liou and Hunt 1996; Izquierdo 1999) since the air elasticity is much higher in comparison with pipe and the water elasticity. Several authors confirm that elastic and rigid flow models provide similar results when filling operations are performed (Abreu et al. 1999; Zhou and Karney 2013a). The majority of current research about filling operations focus when air valves are not acting. The proposed mathematical model has been validated in experimental 
facilities considering air valves at the Universitat Politècnica de València (Polytechnic University of Valencia) (Fuertes-Miquel 2001) and the Universidade de Lisboa (University of Lisbon) (Coronado-Hernández et al. 2019). Despite the filling operation using air valves has been studied applying different experimental facilities, there are no studies reported in the literature concerning this process in actual pipelines, which is of utmost important to validate the proposed mathematical model for large-scale installations.

The main objective of this study is to apply the proposed mathematical model to large-scale installations and compare the experimental measurements with the results of the model for validation. Applications and limitations of the proposed mathematical model in real-world pipelines are identified. To this end, the filling of cast-iron pipelines with nominal diameters of DN400 and DN600 are analysed; these pipelines are operated by EMIMET (Group Global Omnium), the company that manages the water supply network of the metropolitan area of Valencia (from the Drinking Water Treatment Station to the municipalities).

\section{Development of the study}

By using a mathematical model that simulates the desired processes, the filling of different sections from the supply network of the Metropolitan Area of Valencia (Spain) is analysed. This facility is managed by EMIMET. This company provided all the measurement values for the subsequent comparisons and analyses.

The facilities that were used for the study are divided into two groups. First, two different sections of a network with a nominal diameter of DN400 are analysed. Then, the same process is performed with three sections of a network with a nominal diameter of DN600, which results is the analysis of a total of five different sections, each with particular geometric characteristics.

Figure 1 shows the geographical location of the two networks mentioned above. The route of the DN400 pipeline is shown in blue, and the abscissas are shown in the map. In the same figure, the geographic location of the other pipeline with a nominal diameter DN600 is shown in red; this pipeline is longer and covers a larger surface area.

In the following section, the work developed to obtain the required results and the subsequent conclusions are shown in detail. 


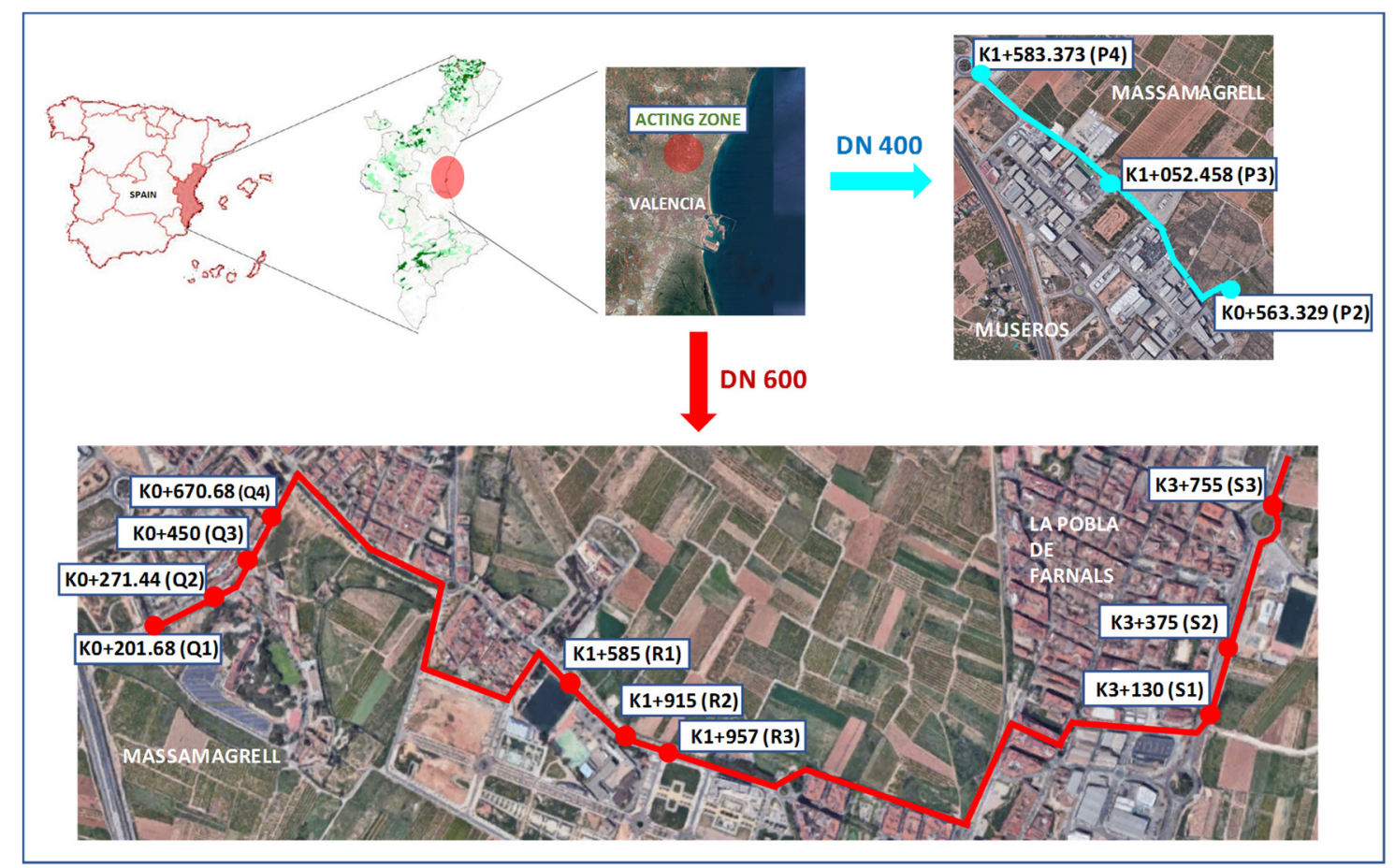

Figure 1. Geographic location of the analysed networks.

\subsection{DN400 Installation}

In this portion of the study, a section of cast iron pipeline with a nominal diameter of DN400 that is located between the municipalities of Massamagrell and Museros in the province of Valencia, Spain, is considered. Figure 1 (blue curve) shows the geographical location of the network.

The total length of this section is $1020 \mathrm{~m}$ from abscissa K0+563.329 (point P2) to abscissa K1+583.373 (point P4). Different valves are installed between the two endpoints, and the following observations can be highlighted: a DN100 gate valve that is responsible for allowing drainage is located at point P2; two DN50 air valves are located along the pipeline to allow the release of air during the filling process; and three DN400 butterfly valves are installed at points $\mathrm{P} 2, \mathrm{P} 3$ and $\mathrm{P} 4$ and are responsible for allowing the passage of water or isolating the full length of the rest of the network.

The two air valves are installed at specific points of the analysed section. Air valve No. 1 is at abscissa K1+052.458 (point P3) at the end of a section with a very slight slope (almost horizontal), while air valve No. 2 is at the end with the highest elevation of the installation (point P4) to allow the release of air at the end of filling and thus prevent significant overpressures. Figure 2 shows a detailed diagram of the installation under analysis for the study of the filling process. The position of the various valves and the slope of each of the sections are shown in this figure. 


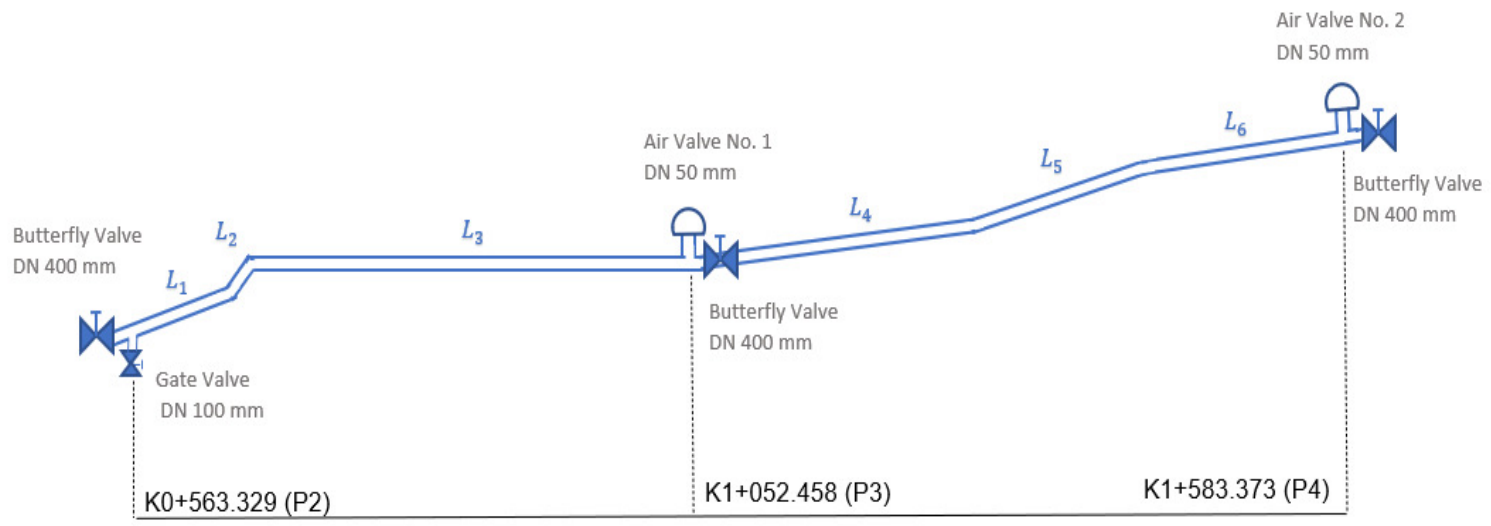

Figure 2. Diagram of the DN400 installation.

This network will be divided into two different sections to conduct the tests. The first of these sections is from abscissa $\mathrm{K} 0+563.329$ (P2) to $\mathrm{K} 1+052.458$ (P3), for a total of $489 \mathrm{~m}$, and an air valve is installed at the upper end. The second section consists of the remaining pipeline, which covers a total length of $531 \mathrm{~m}$ from abscissa K1+052.458 (P3) to $\mathrm{K} 1+583.373$ (P4). This second section also has only one air valve at point $\mathrm{P} 4$, thereby allowing air exchange with the outside. Both sections are in contact and separated by the butterfly valve located at point $\mathrm{P} 3$.

The valves that allow water entry into the pipeline are the DN400 butterfly valves located at points P2 and P3. The collaborating company, EMIMET, provided a comprehensive analysis of these valves to obtain the coefficient $K_{v}$. Equation (1), based on empirical studies, is used for this calculation, where the $A, B, C, D$ and $E$ values are obtained according to the number of opening turns for the valve.

$$
K_{v}=A+B \cdot P_{s}+C \cdot D_{p}+D \cdot P_{s}^{2}+E \cdot D_{p}^{2}
$$

Where $P_{s}$ is the outlet pressure in wcm, $\Delta p$ is the pressure difference in wcm and $K_{v}$ is the coefficient of the butterfly valve in $\mathrm{m}^{3} / \mathrm{h} / \mathrm{bar}^{0.5}$. For a DN400 valve, the values obtained are $K_{v}=90.33 \mathrm{~m}^{3} / \mathrm{h} / \mathrm{bar}^{0.5}$ for the P2-P3 filling and $K_{v}=208.75 \mathrm{~m}^{3} / \mathrm{h} / \mathrm{bar}^{0.5}$ for the P3-P4 filling.

\subsubsection{Mathematical Model}

A mathematical model is proposed to analyse the filling processes in pressurized pipelines. The main assumptions are as follows:

- The rigid model is used to simulate the movement of the water column. This assumption is valid because the elasticity of air is much greater than that of water and of the pipe.

- The piston flow model is used to simulate the air-water interface. This means that the air-water interface is perpendicular to the axis of the pipe.

- The polytropic model is used to simulate the behaviour of air. 
- Both the friction factor and the polytropic coefficient are considered constant throughout the transient phenomenon.

The system of equations that models the filling process can be established with equations that model the behaviour of the water column and other equations that model the behaviour of the air pocket. The set of equations used is presented below.

\section{$\underline{\text { FILLING COLUMN }}$}

- Equation of the rigid model that characterises the movement of the filling column driven by the power source ( $p_{0}^{*}$ is the upstream pressure of the pipeline, and $p_{1}^{*}$ is the pressure of the air pocket):

$$
\frac{d v}{d t}=\frac{p_{0}^{*}-p_{1}^{*}}{\rho_{w} L_{e}}-g\left(\frac{\Delta z}{L_{e}}\right)-f \frac{v|v|}{2 D}-\frac{R_{v} g A^{2} v|v|}{L_{e}}
$$

- Position of the filling column:

$$
\frac{d L_{e}}{d t}=+v \quad o \quad L_{e}=L_{0}+\int_{0}^{t} v d t
$$

Where $v$ is the velocity of the filling column, $p_{0}^{*}$ is the absolute pressure upstream of the pipeline, $p_{1}^{*}$ is the absolute pressure of the air pocket, $L_{e}$ is the length of the filling column, $\rho_{w}$ is the density of water, $D$ is the diameter of the pipe, $g$ is the acceleration of gravity, $\frac{\Delta z}{L_{e}}$ is the gravitational term, $f$ is the friction factor, $R_{v}$ is the drag coefficient of the valve and $A$ is the cross section of the pipe.

\section{$\underline{\text { AIR POCKET }}$}

- Air pocket evolution:

$$
\frac{d p_{1}^{*}}{d t}=\frac{p_{1}^{*} k}{\left(L_{T}-L_{e}\right)}\left(v-\frac{v_{a C N} A_{\text {exp }}}{A}\right)
$$

- Continuity equation of the air pocket:

$$
\frac{d \rho_{a}}{d t}=\frac{-\rho_{a} v_{a C N} A_{e x p}+v A \rho_{a}}{\left(L_{T}-L_{e}\right) A}
$$

- Characteristic equation of the air valve during the filling process:

$$
v_{a C N}=C_{\text {exp }} p_{1}^{*} \sqrt{\frac{7}{R T}\left[\left(\frac{p_{a t m}^{*}}{p_{1}^{*}}\right)^{1.4286}-\left(\frac{p_{a t m}^{*}}{p_{1}^{*}}\right)^{1.714}\right]}
$$


Where $k$ is the polytropic coefficient, $L_{T}$ is the total length of the installation, $A_{\text {exp }}$ is the cross-sectional area of the air valve, $\rho_{a}$ is the density of the air pocket, $C_{\text {exp }}$ is the outflow discharge coefficient of the air valve and $Q_{a}$ is the flow rate of air expelled by the air valve.

In equation (2), the gravitational term stands out; this parameter relates the position of each section with its respective slope. The velocity is a variable that is directly affected by the section where the water column is located. The flatter the route is, the steadier the velocity will be; however, if a duct has a high slope, the velocity will suffer a steep decline. The term will change along the entire route depending on the position of the water column:

If $L_{1}>L_{e} \geq 0$, then:

$$
\frac{\Delta z}{L_{e}}=\sin \theta_{1}
$$

If $L_{1}+L_{2}>L_{e} \geq L_{1}$, then:

$$
\frac{\Delta z}{L_{e}}=\frac{L_{1} \sin \theta_{1}}{L_{e}}+\left(1-\frac{L_{1}}{L_{e}}\right) \sin \theta_{2}
$$

If $L_{1}+L_{2}+L_{3}>L_{e} \geq L_{1}+L_{2}$, then:

$$
\frac{\Delta z}{L_{e}}=\frac{L_{1} \sin \theta_{1}+L_{2} \sin \theta_{2}}{L_{e}}+\left(1-\frac{L_{1}+L_{2}}{L_{e}}\right) \sin \theta_{3}
$$

If $L_{1}+L_{2}+L_{3}+L_{4}>L_{e} \geq L_{1}+L_{2}+L_{3}$, then:

$$
\frac{\Delta z}{L_{e}}=\frac{L_{1} \sin \theta_{1}+L_{2} \sin \theta_{2}+L_{3} \sin \theta_{3}}{L_{e}}+\left(1-\frac{L_{1}+L_{2}+L_{3}}{L_{e}}\right) \sin \theta_{4}
$$

If $L_{T}>L_{e} \geq L_{1}+L_{2}+L_{3}+\cdots+L_{i-1}$, then:

$$
\begin{gathered}
\frac{\Delta z}{L_{e}}=\frac{L_{1} \sin \theta_{1}+L_{2} \sin \theta_{2}+L_{3} \sin \theta_{3}+\cdots+L_{i-1} \sin \theta_{i-1}}{L_{e}} \\
+\left(1-\frac{L_{1}+L_{2}+L_{3}+\cdots+L_{i-1}}{L_{e}}\right) \sin \theta_{i}
\end{gathered}
$$


Where $i$ represents the total number of sections, $L_{j}$ is the length of a specific section $j$ and $\theta_{j}$ represents the longitudinal slope of section $j$. With this analysis, it is possible to simulate a system with numerous sections with different slopes.

\subsubsection{Air Valves Capacity Charts}

To achieve a filling process without large overpressures, two air valves with nominal diameters of DN50 are installed, as shown in Figure 2. In this case, it is only necessary to obtain the outflow discharge coefficient $\left(C_{\text {exp }}\right)$ of the air valve because the analysis is for the filling process. The manufacturer provides air valves capacity charts in its catalogue. To obtain the outflow discharge coefficient of the air valve, the data provided by the manufacturer have been fitted to equation (6), which is the characteristic equation of the air valve (Wylie and Streeter 1993). After the corresponding adjustment, the value of the outflow discharge coefficient is $C_{\text {exp }}=0.61$.

\subsubsection{Initial and Boundary Conditions}

The initial conditions of the various hydraulic variables for the analysis of the two filling processes of the DN400 pipeline are as follows: $v(0)=0 ; L_{e}(0)=0 m ; p_{1}^{*}(0)=$ $101325 \mathrm{~Pa} ; \rho_{a}(0)=1.205 \mathrm{~kg} / \mathrm{m}^{3} ; v_{a C N}(0)=0$; and $Q_{a}(0)=0$.

An upstream constant absolute pressure $\left(p_{0}{ }^{*}\right)$ of $389704 \mathrm{~Pa}$ was considered for the first section P2-P3, while a value of $358315 \mathrm{~Pa}$ was used for the second section P3-P4. Atmospheric pressure conditions (101325 Pa) were considered on the outside of the pipe.

In addition, other critical data include the friction factor, used to calculate pipeline losses $(f=0.0257)$, and the value of the polytropic coefficient, used to model the behaviour of the air pocket $(k=1.1)$.

\subsubsection{Results}

The software programme used to solve the system of equations that make up the mathematical model was MATLAB with the Simulink tool. The obtained results are compared to experimental measurements made by EMIMET to validate the proposed mathematical model.

The results obtained in this installation are shown below. It should be noted that the pressures and water flows inside the pipes are the only experimental measurements available. For that reason, pressure and flow comparison charts are shown. Subsequently, based on the results provided by the mathematical model, the evolution of other variables is presented.

1) Section $\mathrm{P} 2-\mathrm{P} 3$ 
Figure 3 shows the evolution of the flow throughout the entire route. The total filling time is 1530 seconds. The blue curve shows the evolution of the experimental measurements, while the orange curve represents the results of the mathematical model. A constant water velocity of $0.32 \mathrm{~m} / \mathrm{s}$ is practically occurring from 25 to 1510 seconds.

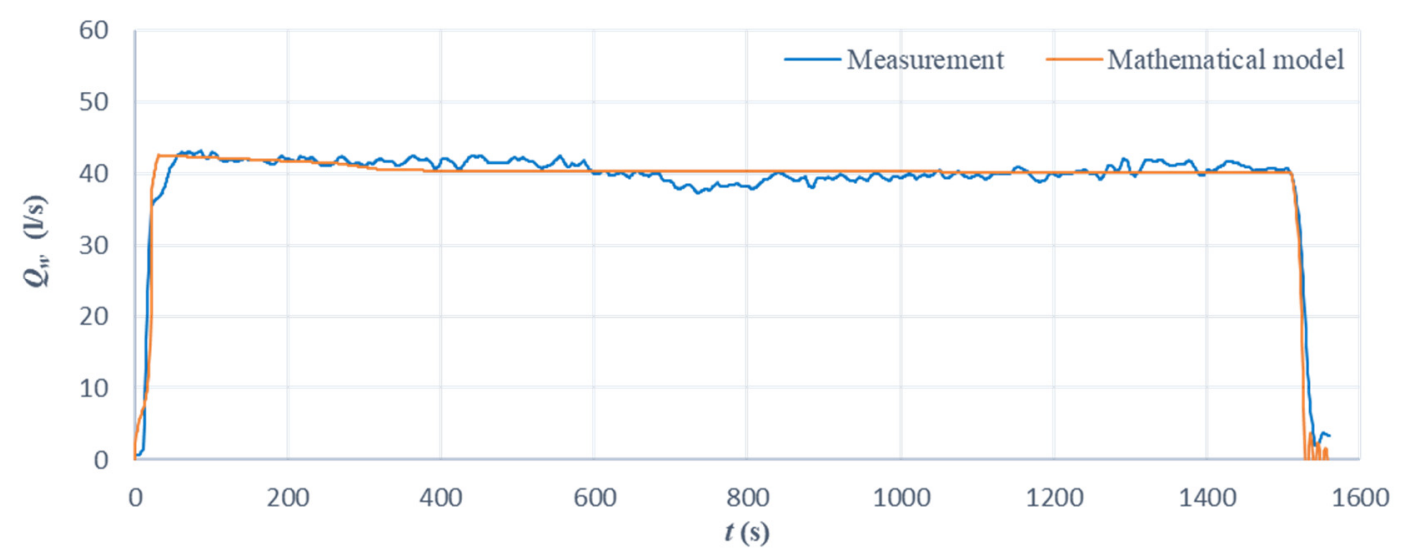

Figure 3. Evolution of the inflow in section P2-P3. Comparison between measurements and the mathematical model.

Figure 4 shows the absolute pressure inside the piping for the same process. It is noticeable how the pressure rises sharply at the end of the process.

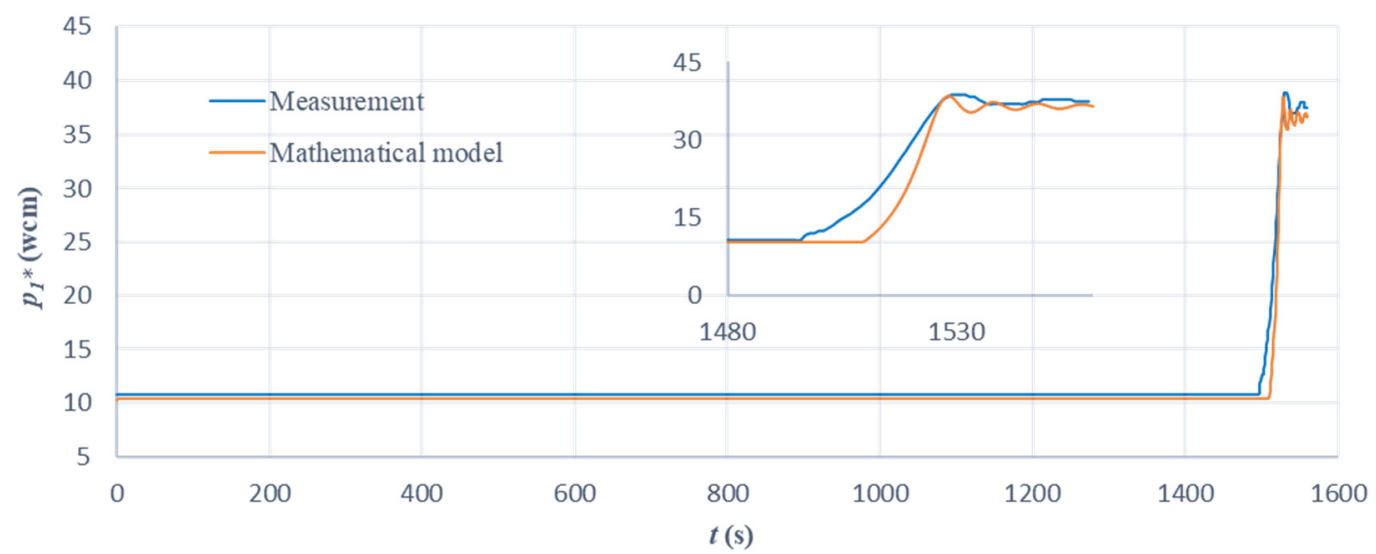

Figure 4. Evolution of the absolute pressure in the air pocket during the filling process of section P2-P3. Comparison between measurements and the mathematical model.

\section{2) Section $\mathrm{P} 3-\mathrm{P} 4$}

As in the previous section, the measurements obtained with the mathematical model are compared to the experimental values. Figure 5 shows the inflow, and Figure 6 shows the absolute pressure. Here, the water velocity presents a decreasing trend from $0.75 \mathrm{~m} / \mathrm{s}(t=$ $20 \mathrm{~s})$ to $0.67 \mathrm{~m} / \mathrm{s}(t=753 \mathrm{~s})$. 


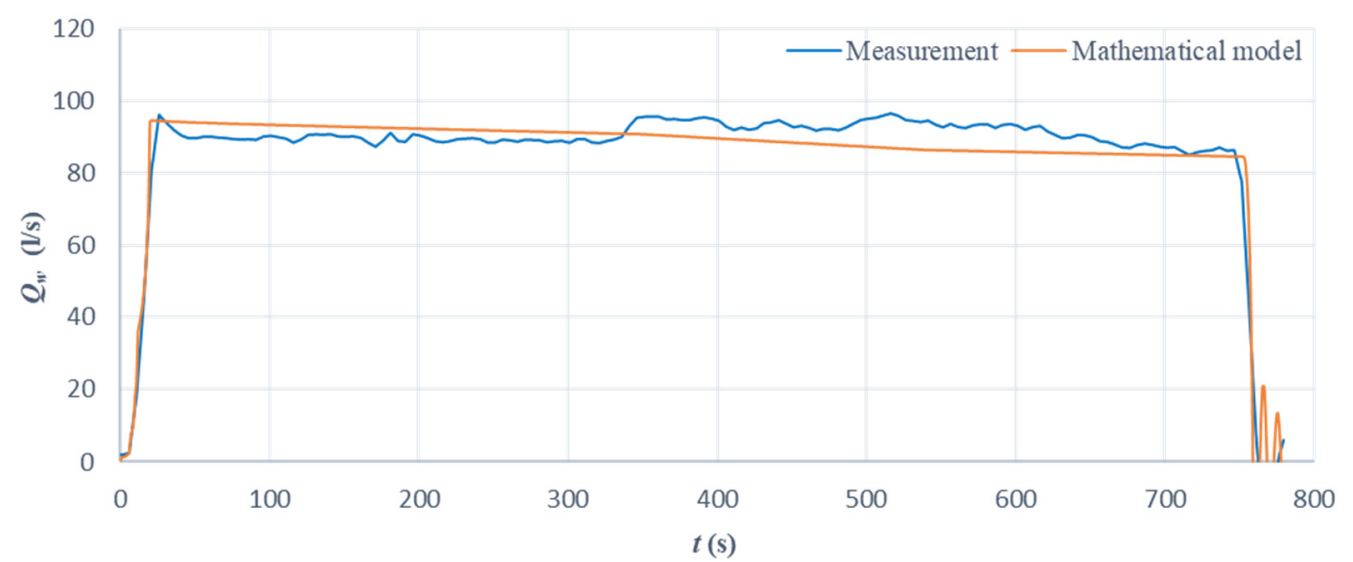

Figure 5. Evolution of the inflow of section P3-P4. Comparison between measurements and the mathematical model.

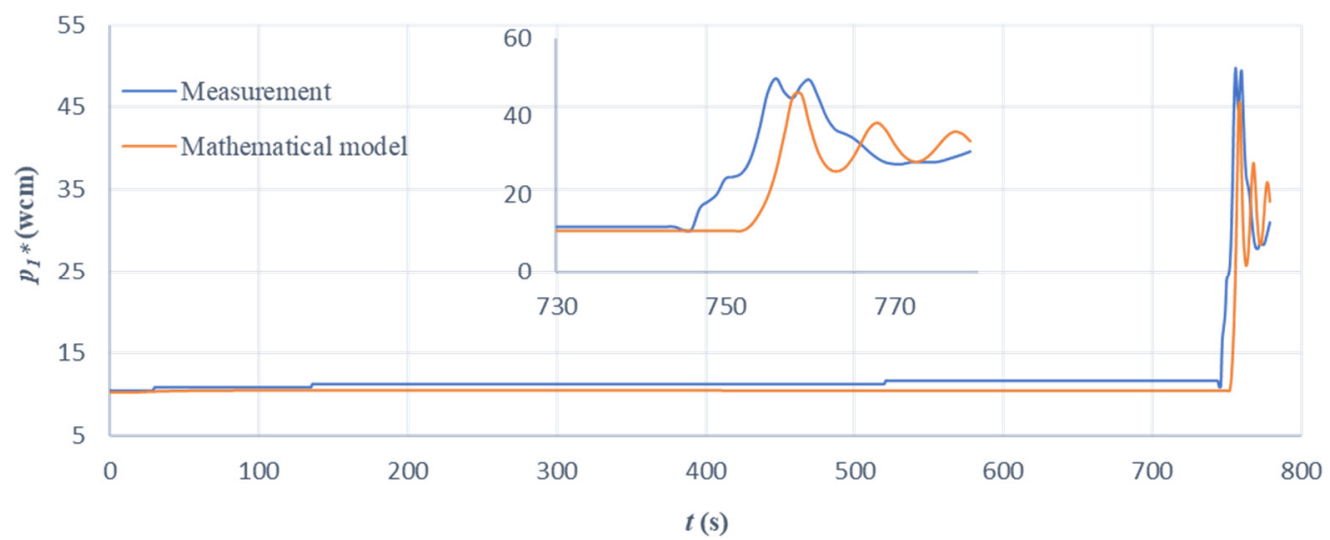

Figure 6. Evolution of the absolute pressure in the air pocket during the filling process of section P3-P4. Comparison between measurements and the mathematical model.

\subsection{DN600 Installation}

The second network analysed in this study consists of a cast iron pipeline with a nominal diameter of DN600, located between the municipalities of Massamagrell and La Pobla de Farnals, in the province of Valencia, Spain. Its geographical location is shown in Figure 1 (red curve).

In this case, the total length of the pipe is $3755 \mathrm{~m}$. Because this pipe spans a very long distance, the decision was made to select isolated sections within this same network to perform a larger number of simulations. An effort was made to choose sections with different geometric characteristics to observe the similarities and discrepancies in the results of each case.

Below, each of the sections analysed in this study is described. First, there is a pipe that goes from abscissa K3+130 (point S1) to abscissa K3+755 (point S3). The total length of this first section is $625 \mathrm{~m}$, and it includes two DN600 butterfly valves and two DN80 air valves at both ends. In the centre of the installation at point S2, there is a DN200 gate valve for drainage of the section.

Figure 7 shows a complete diagram of section S1-S3. 


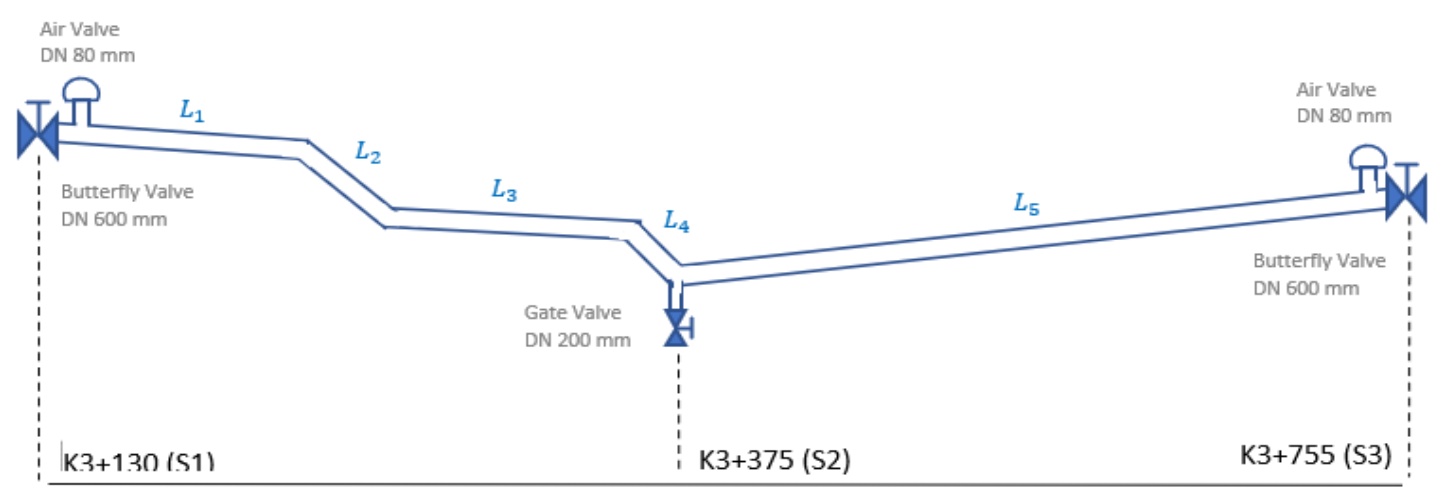

Figure 7. Diagram of section S1-S3.

Finally, an analysis is done on the filling of a pipeline with a nominal diameter of DN600 and a total length of $469 \mathrm{~m}$, with a high point located approximately in the middle of the section (point Q3). The route goes from abscissa K0+201.68 (point Q1) to abscissa $\mathrm{K} 0+670.68$ (point Q4). The peculiarity of this section is that it has a DN80 air valve halfway along the route at the highest point (Q3). Figure 8 shows in detail the entire section and the location of each element.

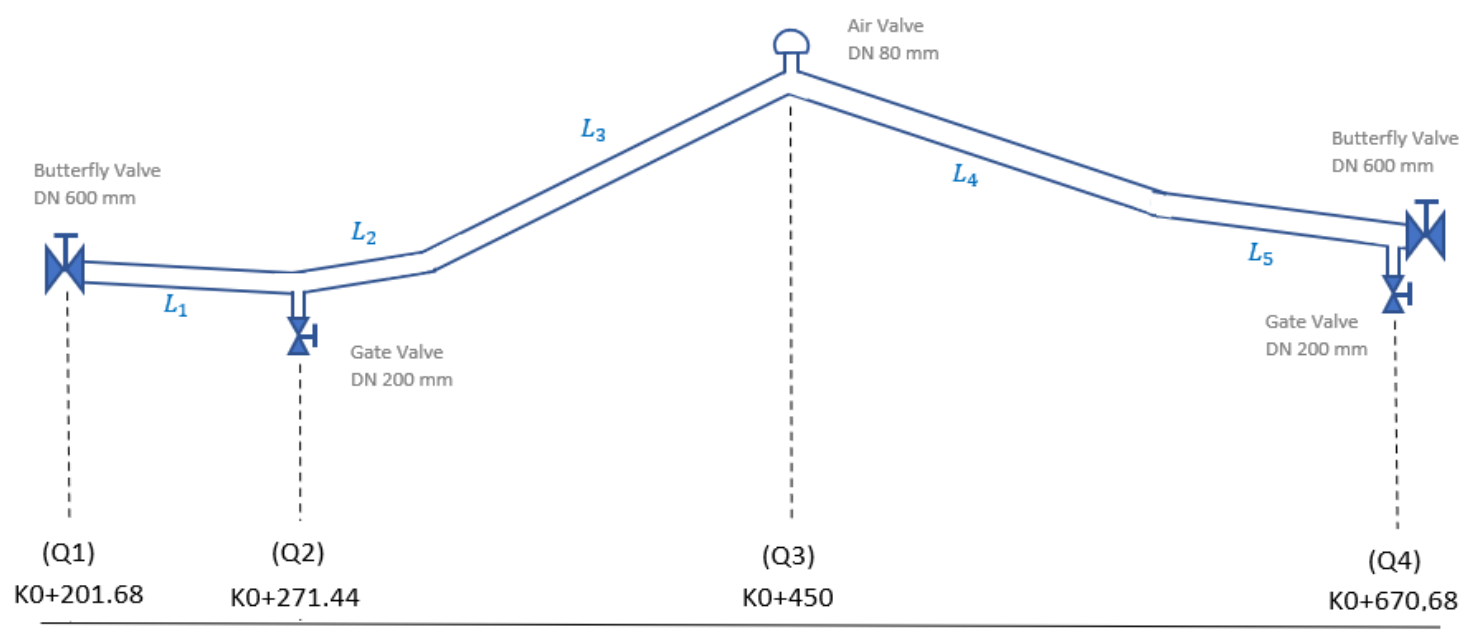

Figure 8. Diagram of section Q1-Q4.

In all cases, the valves that allow water to flow and fill the pipes are DN600 butterfly valves. To obtain a realistic simulation, the $K_{v}$ coefficients of the valves have to be obtained and entered in the simulation programme according to the valve opening.

As in the previous network, the EMIMET company facilitated a previous study that defined the $K_{v}$ coefficient for the DN600 butterfly valves in $\left(\mathrm{m}^{3} / \mathrm{h} / \mathrm{bar}^{0.5}\right)$. The study is based on equation (1), which defines coefficient $K_{v}$ according to the number of open turns and the inlet and outlet pressures.

Based on empirical studies, the coefficient of the valves in each of the processes can be obtained. For the first case for section S1-S3, a $K_{v}$ coefficient of $278.8 \mathrm{~m}^{3} / \mathrm{h} / \mathrm{bar}^{0.5}$ is obtained. Finally, the valves of section Q1-Q4 operate with a $K_{v}$ coefficient of 296.8 $\mathrm{m}^{3} / \mathrm{h} / \mathrm{bar}^{0.5}$. 


\subsubsection{Mathematical Model}

To represent the processes tested in this installation, the same differential equations described in the previous case will be used, based on the same assumptions. For the filling process, in which there is only one water column and one air pocket inside the pipeline, the equations have the same form.

In this case, there are equations that define the evolution of the column filling: the rigid model equation and the equation of the position of the water column. Likewise, there are equations that describe the behaviour of the air pocket: the evolution of the air pocket, the continuity equation for the air pocket and the characteristic equation of the air valve.

It is only necessary to consider the number of sections that divide each pipe length and the respective slope because the gravitational term can be affected by the geometrical characteristics of each installation.

\subsubsection{Air Valves Capacity Charts}

Similar to what was done for the DN400 network, to study the process of filling, it is necessary to obtain the outflow discharge coefficient $\left(C_{\text {exp }}\right)$ of the DN80 air valve. Equation (6) is adjusted based on data provided by the manufacturer in its catalogue. The final comparison between the venting capacity chart provided by the manufacturer and the adjusted curve yields an outflow discharge coefficient value of $C_{\text {exp }}=0.53$, which corresponds to the DN80 air valve.

\subsubsection{Initial and Boundary Conditions}

For the analysis of the filling processes of the DN600 pipeline, the initial conditions of the various hydraulic variables are as follows: $v(0)=0 ; L_{e}(0)=0 m ; p_{1}^{*}(0)=$ $101325 \mathrm{~Pa} ; \rho_{a}(0)=1.205 \mathrm{~kg} / \mathrm{m}^{3} ; v_{a C N}(0)=0$; and $Q_{a}(0)=0$.

An upstream constant absolute pressure $\left(p_{0}^{*}\right)$ of $425911 \mathrm{~Pa}$ was considered for DN600 installation. Atmospheric pressure conditions (101325 Pa) were considered on the outside of the pipe.

In addition, other critical data include the friction factor, used to calculate pipeline losses (in this case, $f=0.023$ ), and the value of the polytropic coefficient, used to model the behaviour of the air pocket $(k=1.1)$, as in the previous case.

\subsubsection{Results}

Having described all the pipelines that will be simulated and analysed, the results obtained for each section are shown for the purpose of comparing them with the experimental measurements and determining if the model can be validated for real large-scale installations.

These parameters are obtained in the same manner as the results shown in the previous section. The software used was MATLAB with the Simulink tool. 


\section{1) Section $\mathrm{S} 1-\mathrm{S} 3$}

The evolution of the inflow is shown in Figure 9. In this figure, the curve of the mathematical model has essentially the same shape as the measurement curve. The process lasts a total of 1260 seconds with a mean water velocity of $0.5 \mathrm{~m} / \mathrm{s}$.

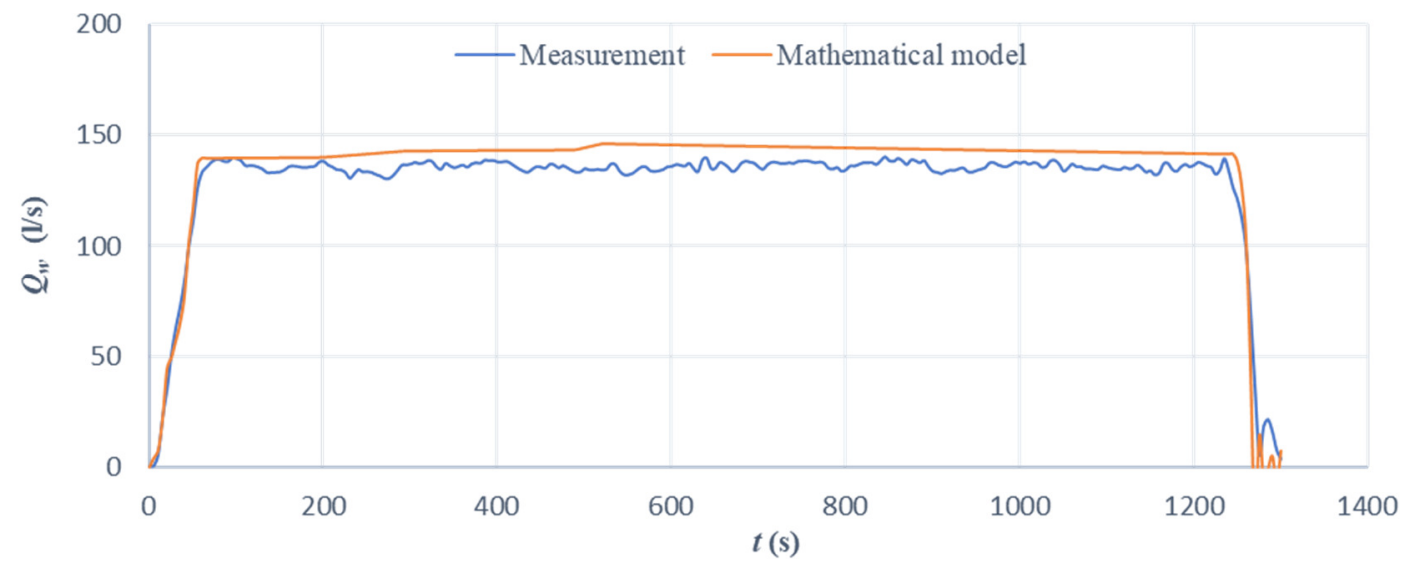

Figure 9. Evolution of the inflow of section S1-S3. Comparison between measurements and the mathematical model.

\section{2) Section Q1-Q4}

For this last section, all graphs from the MATLAB programme are shown for further analysis. The comparisons between the experimental measurements and the results of the model for both the inflow that fills the pipe (Figure 10) and the absolute pressure of the air inside the pipe (Figure 11) are presented.

The filling process lasts 940 seconds ( 15.7 minutes), and in this time, the entire section is filled. Figure 10 shows the flow during filling. It can be observed that the mathematical model provides good results for the first part of the process where the water velocity drops from $0.59 \mathrm{~m} / \mathrm{s}$ to $0.53 \mathrm{~m} / \mathrm{s}$. However, when the water column reaches the highest point and begins the downward stretch, significant discrepancies appear between the results of the model and the experimental measurements.

In addition, Figure 11 shows the pressure of air inside the pipe, which remains virtually constant with a value close to atmospheric pressure until the water column reaches the air valve and a pressure surge occurs that is clearly noticeable in the graph. 


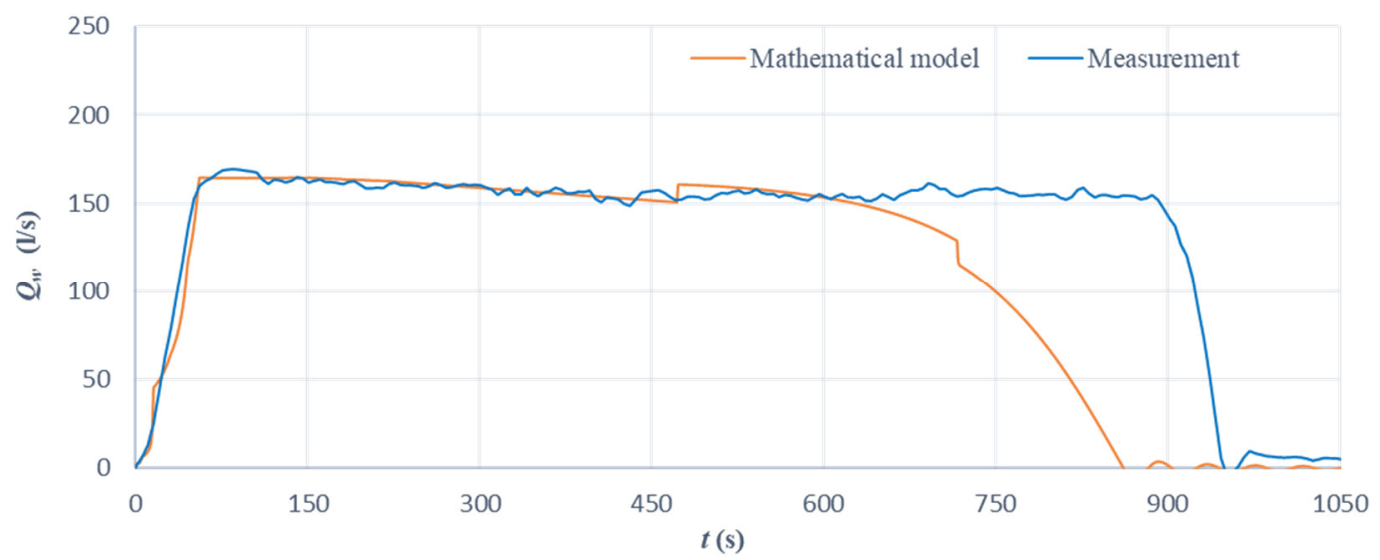

Figure 10. Evolution of the inflow of section Q1-Q4. Comparison between measurements and the mathematical model.

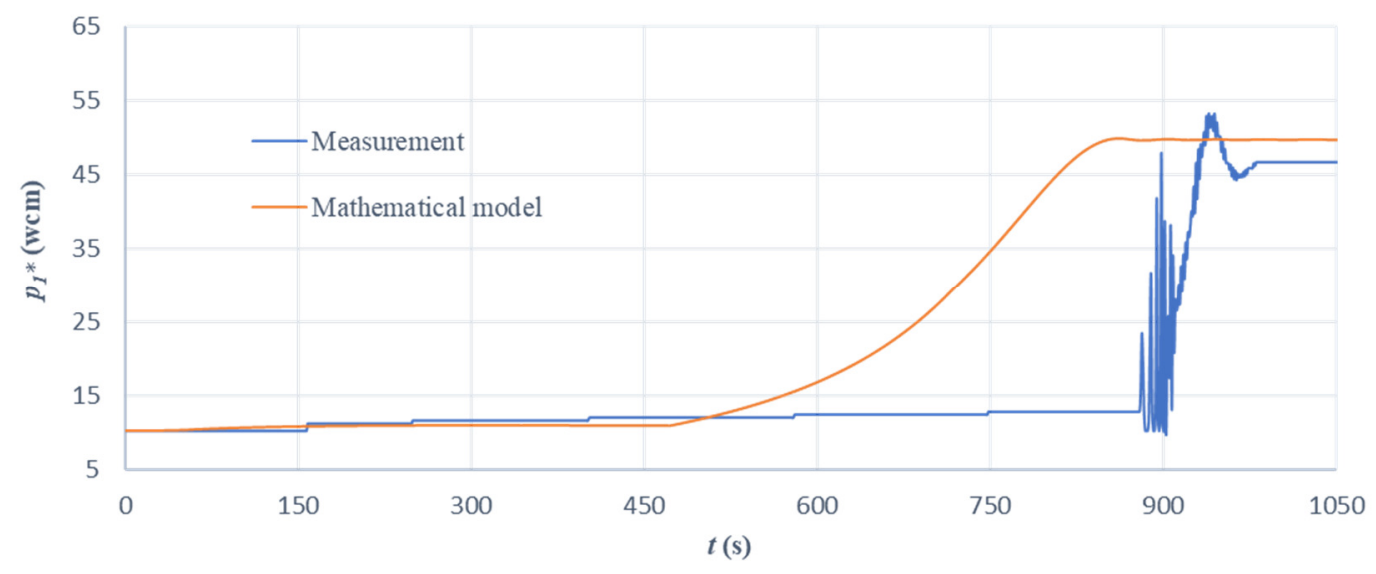

Figure 11. Evolution of the absolute pressure in the air pocket during the filling process of section Q1-Q4. Comparison between measurements and the mathematical model.

\section{Discussion}

First, an analysis is done on the filling processes of two pipelines with a nominal diameter DN400 and total lengths of 489 and $531 \mathrm{~m}$. In these first cases, it is clearly noticeable that the results provided by the model are very similar to the experimental measurements. For example, Figure 3 shows the great similarity between the curves with the process ending at the same time. Figure 4 shows that at the end of filling, the pressure increases sharply until it reaches a maximum value, begins to oscillate and finally stabilises. This process occurs because the water column reaches the air valve and prevents the escape of more air, producing a substantial overpressure inside the pipe.

Second, the filling processes are also analysed at different sections that are part of a network with a nominal diameter of DN600 and a total length exceeding 3,700 m. In the first case studied, the conclusion reached is the same as that in the DN400 network. However, if the analyses are concentrated on the latter case (K0+201.68 to K0+670.68), then discrepancies occur between the results of the mathematical model and the experimental measurements (Figures 10 and 11), thereby requiring a more detailed analysis. 
The analysis of this specific case shows that during the first 465 seconds, the similarity between the model and the measurements is indisputable. First, the error between the mathematical model and reality is practically non-existent. However, from that moment on, discrepancies are obvious, and the mathematical model predicts faster pipeline filling (Figure 12). It is of utmost importance to introduce a stratified flow formulation in the non-pressurized region for the one-dimensional mathematical model to improve discrepancies between experimental measurements and computed values of hydraulic and thermodynamic variables. Alternatively, the entire pipeline can be simulated using Computational Fluids Dynamics techniques.

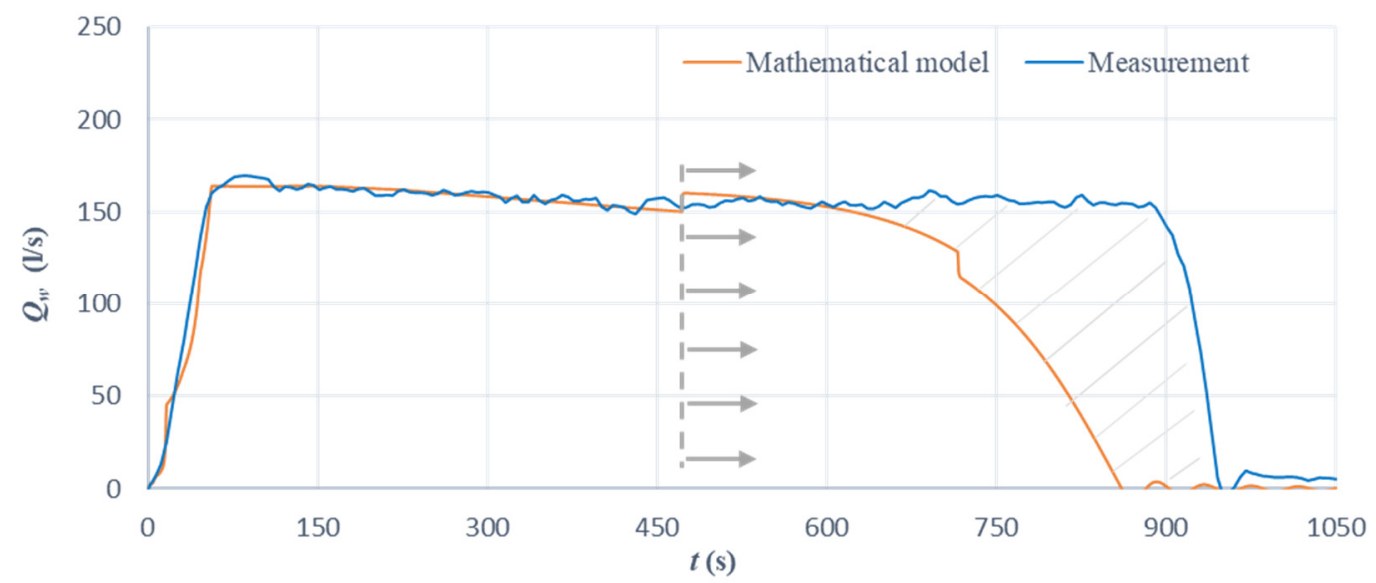

Figure 12. Discrepancies between the results of the mathematical model and the experimental measurements.

The discrepancies occur when the water column reaches the air valve installed at the highest point (point Q3). From that moment, the water column starts to move in the descending section. One of the main assumptions of the proposed mathematical model is the use of the piston flow model to simulate the air-water interface, namely, the air-water interface coincides with the straight section of the pipeline. This means that in a straight section of pipe there is air or water, but there is never part water and part air.

In the case studied, when the water column reaches the highest point and starts to move in the descending section, this hypothesis is no longer satisfied. In this descending section, water moves at the bottom of the pipe and leaves an air pocket at the top. As a result, the air valve is not fully closed and still allows air to flow. Obviously, under these conditions, the results provided by the mathematical model do not resemble what truly happens. For this reason, in Figures 10 and 11, there are differences between the results of the model and the experimental measurements in the second part of the filling process, just as the water column reaches the highest point.

\section{Conclusions}

This study used the mathematical model proposed by the authors to analyse filling processes in real large-scale installations with installed air valves, with the ultimate goal of validating the mathematical model. 
It can be asserted that the mathematical model proposed for the analysis of the filling processes of pressurised pipelines is perfectly valid if the assumptions of the model are satisfied since the comparison between experimental measurements and results of the mathematical models confirmed it.

When the piston flow model assumption is no longer satisfied, discrepancies will occur, and the proposed model will no longer be valid. The occurrence of this phenomenon is presented when the air-water front reached the highest point of the pipelines, where a stratified flow model began inside them.

The proposed model will enable companies responsible for water distribution networks to study the filling processes and determine beforehand the maximum overpressures that will be reached depending on how the processes are performed.

To conclude, it should be highlighted that the ability to perform tests and measurements in real large-scale installations is of great interest. In many cases, models are validated with small laboratory facilities, but measurements from real systems are not available. This research validated the proposed mathematical model using data of realworld pipelines during filling operations with air valves.

\section{Acknowledgements}

This study was made possible thanks to the collaboration between the Universitat Politècnica de València (UPV) and Empresa Mixta Metropolitana S.A. (EMIMET Group Global Omnium), the company that provided the experimental measurements for real large-scale installations.

\section{Nomenclature / Notation}

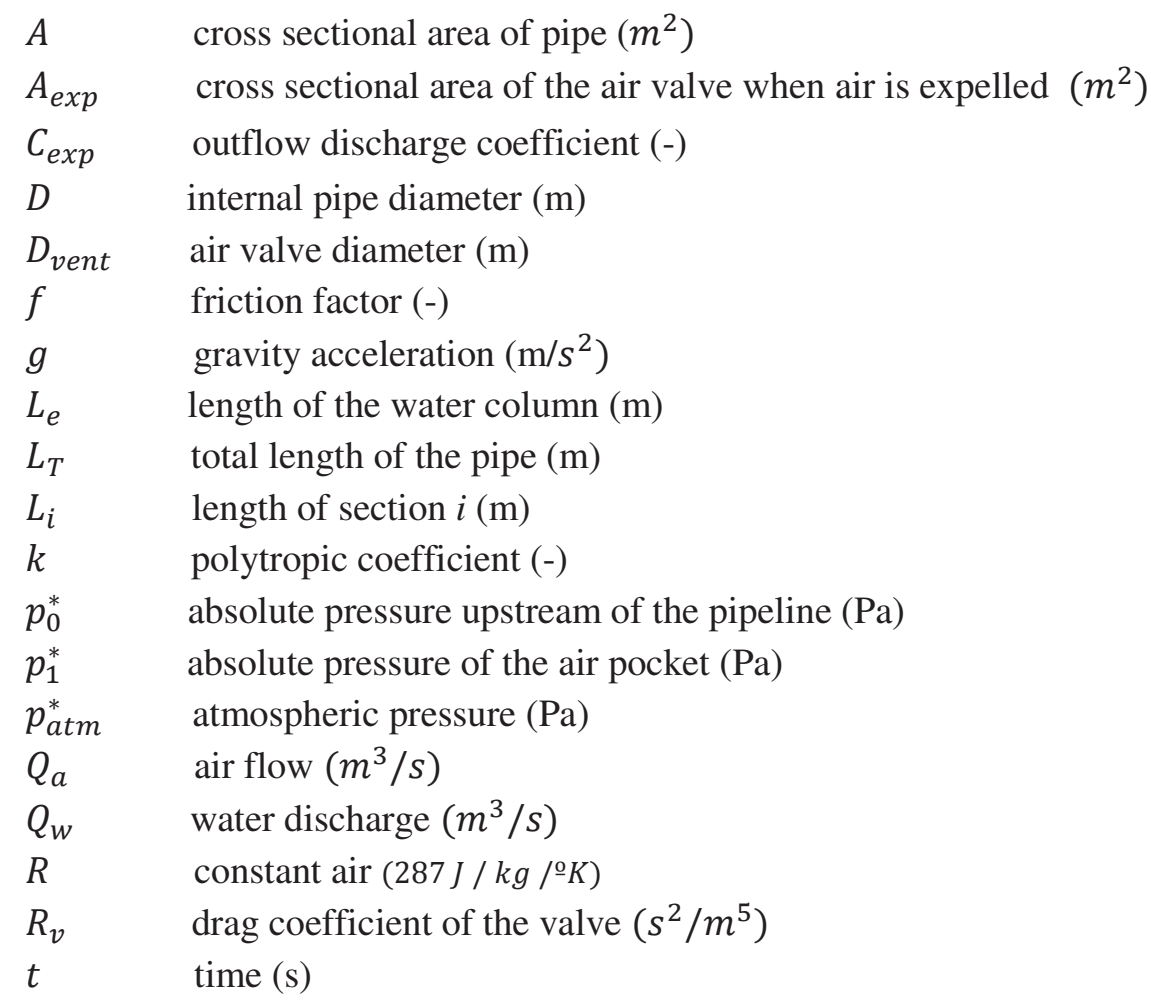


$v \quad$ water velocity $(\mathrm{m} / \mathrm{s})$

$v_{a C N} \quad$ air velocity $(\mathrm{m} / \mathrm{s})$

$z \quad$ elevation (m)

$\Delta z \quad$ difference elevation (m)

$\rho_{w} \quad$ water density $\left(\mathrm{kg} / \mathrm{m}^{3}\right)$

$\rho_{a} \quad$ air density $\left(\mathrm{kg} / \mathrm{m}^{3}\right)$

$\theta_{i} \quad$ pipe inclination (\%)

\section{Superscripts}

* absolute values

\section{Subscripts}

$\begin{array}{ll}a & \text { refers to air } \\ i & \text { refers to section of the pipe } \\ n c & \text { refers to normal conditions } \\ w & \text { refers to water } \\ 0 & \text { refers to initial conditions }\end{array}$

\section{References}

Abreu, J., E. Cabrera, J. Izquierdo, and J. García-Serra. 1999. "Flow Modeling in Pressurized Systems Revisited.” Journal of Hydraulic Engineering 125 (11): 1154-1169.

AWWA. 2001. American Water Works Association (AWWA). Manual of Water Supply Practices - M51: Air-Release, Air-Vacuum, and Combination Air Valves. 1st ed. Denver, CO, USA: Denver.

Apollonio, C., G. Balacco, N. Fontana, M. Giugni, G. Marini, and A.F. Piccinni. 2016. "Hydraulic Transients Caused by Air Expulsion during Rapid Filling of Undulating Pipelines." Water 8 (1): 25.

Balacco, G., C. Apollonio, and A.F. Piccinni. 2015. "Experimental Analysis of Air Valve Behaviour During Hydraulic Transients." Journal of Applied Water Engineering and Research 3 (1): 3-11.

Balacco, G., N. Fontana, C. Apollonio, M. Giugni, G. Marini, and A.F. Piccinni. 2018. "Pressure Surges during Filling of Partially Empty Undulating Pipelines." ISH Journal of Hydraulic Engineering 1 (9).

Besharat, M., R. Tarinejad, M.T. Aalami, and H.M. Ramos. 2016. "Study of a compressed air vessel for controlling the pressure surge in water networks: CFD and experimental analysis." Water Resources Management, 30 (8): 2687-2702.

Chaudhry, M. H. 2014. Applied Hydraulic Transients. Columbia. SC, USA: Springer.

Coronado-Hernández, O.E., V.S. Fuertes-Miquel, M. Besharat, and H.M. Ramos. 2018. "Subatmospheric Pressure in a Water Draining Pipeline with an Air Pocket." Urban Water Journal 15 (4): 346-352. 
Coronado-Hernández, O.E., M. Besharat, V.S. Fuertes-Miquel, and H.M. Ramos. 2019. "Effect of a commercial air valve on the rapid filling of a single pipeline: a numerical and experimental analysis." Water 11 (9): 1814.

Fuertes-Miquel, V.S. 2001. "Hydraulic Transients with Entrapped Air Pockets." PhD diss., Department of Hydraulic Engineering, Polytechnic University of Valencia, Spain.

Fuertes-Miquel, V.S., O.E. Coronado-Hernández, D. Mora-Meliá, and P.L. Iglesias-Rey. 2019a. "Hydraulic modelling during filling and emptying processes in pressurized pipelines: a literature review." Urban Water Journal 16 (4): 299-311.

Fuertes-Miquel, V.S., O.E. Coronado-Hernández, P.L. Iglesias-Rey and D. Mora-Meliá. 2019b. "Transient phenomena during the emptying process of a single pipe with water-air interaction." Journal of Hydraulic Research 57 (3): 318-326.

García-Todolí, S., P.L. Iglesias-Rey, D. Mora-Meliá, F.J. Martínez-Solano, and V.S. FuertesMiquel. 2018. "Computational Determination of Air Valves Capacity Using CFD Techniques." Water 10 (10): 1433.

Hou, Q., A. Tijsseling, J. Laanearu, I. Annus, T. Koppel, A. Bergant, S. Vuković, A. Anderson, and J. Van'tWestende. 2014. "Experimental investigation on rapid filling of a large-scale pipeline." Journal of Hydraulic Engineering 140 (11).

Izquierdo, J., V.S. Fuertes, E. Cabrera, P.L. Iglesias, and J. García-Serra. 1999. "Pipeline Startup with Entrapped Air.” Journal of Hydraulic Research 37 (5): 579-590.

Laanearu, J., I. Annus, T. Koppel, A. Bergant, S. Vučković, Q. Hou, A.S. Tijsseling, A. Anderson, and J.M.C. Van't Westende. 2012. "Emptying of Large-scale Pipeline by Pressurized Air." Journal of Hydraulic Engineering 138 (12): 1090-1100.

Leon, A., M. Ghidaoui, A. Schmidt, and M. Garcia. 2010. "A Robust Two-equation Model for Transient-mixed Flows." Journal of Hydraulic Research 48 (1): 44-56.

Liou, C., and W.A. Hunt. 1996. "Filling of Pipelines with Undulating Elevation Profiles." Journal of Hydraulic Engineering 122 (10): 534-539.

Malekpour A., and B.W. Karney. 2014. Discussion of "Pressure Surges Following Sudden Air Pocket Entrapment in Storm-Water Tunnels" by Jose G. Vasconcelos and Gabriel M. Leite. Journal of Hydraulic Engineering 140 (4).

Malekpour, A., B.W. Karney, and J. Nault. 2016. "Physical Understanding of Sudden Pressurization of Pipe Systems with Entrapped Air: Energy Auditing Approach." Journal of Hydraulic Engineering 142 (2): 04015044.

Malekpour A., and B.W. Karney. 2019. "Complex interactions of water, air and its controlled removal during pipeline filling operations." Fluid Mechanics Research International Journal 3 (1): 4-15.

Martins, S.C., H.M. Ramos, and A.B. Almeida. 2015. "Conceptual Analogy for Modelling Entrapped Air Action in Hydraulic Systems." Journal of Hydraulic Research 53 (5): 678-686.

Martins, N.M.C., J.N. Delgado, H.M. Ramos, and D.I.C. Covas. 2017. "Maximum transient pressures in a rapidly filling pipeline with entrapped air using a CFD model." Journal of Hydraulic Research 55 (4): 1-14.

Saemi, S., M. Raisee, M.J. Cervantes, and A. Nourbakhsh. 2019. "Computation of two- and threedimensional water hammer flows.” Journal of Hydraulic Research 57 (3): 386-404.

Ramezani, L., B. Karney, and A. Malekpour. 2015. "The Challenge of Air Valves: A Selective Critical Literature Review." Journal of Water Resources Planning and Management 141 (10): 04015017. 
Ramezani, L., B. Karney, and A. Malekpour. 2016. "Encouraging Effective Air Management in Water Pipelines: A Critical Review." Journal of Water Resources Planning and Management 142 (12): 04016055.

Tijsseling, A., Q. Hou, Z. Bozkuş, and J. Laanearu. 2016. "Improved One-Dimensional Models for Rapid Emptying and Filling of Pipelines." Journal of Pressure Vessel Technology 138 (3): 031301.

Tran, P. 2017. "Pressure transients caused by air-valve closure while filling pipelines." Journal of Hydraulic Engineering 143 (2).

Trindade, B.C., and J.G. Vasconcelos. 2013. "Modeling of Water Pipeline Filling Events Accounting for Air Phase Interactions." Journal of Hydraulic. Engineering 139 (9): 921-934.

Vasconcelos, J.G., and S.J. Wright. 2008. "Rapid Flow Startup in Filled Horizontal Pipelines." Journal of Hydraulic Engineering 134 (7): 984-992.

Wang, L., F. Wang, B. Karney, and A. Malekpour. 2017. "Numerical Investigation of Rapid Filling in Bypass Pipelines." Journal of Hydraulic Research 55 (5): 647-656.

Wylie, E., and V. Streeter. 1993. Fluid Transients in Systems. Englewood Cliffs, NJ: Ed. Prentice Hall.

Zhou, F., M. Hicks, and P.M. Steffler. 2002. "Transient Flow in a Rapidly Filling Horizontal Pipe Containing Trapped Air." Journal of Hydraulic Engineering 128 (6): 625-634.

Zhou, L., D. Liu, and C. Ou. 2011. "Simulation of Flow Transients in a Water Filling Pipe Containing Entrapped Air Pocket with VOF Model." Engineering Applications of Computational Fluid Mechanics 5 (1): 127-140.

Zhou, L., D. Liu, and B. Karney. 2013a. "Phenomenon of White Mist in Pipelines Rapidly Filling with Water with Entrapped Air Pocket." Journal of Hydraulic Engineering 139 (10): 10411051.

Zhou, L., D. Liu, B. Karney, and Q. Zhang. 2011. "Influence of Entrapped Air Pockets on Hydraulic Transients in Water Pipelines." Journal of Hydraulic Engineering 137 (12).

Zhou, L., and D. Liu. 2013b. "Experimental Investigation of Entrapped Air Pocket in a Partially Full Water Pipe." Journal of Hydraulic Research 51 (4): 469-474. 